Letter

\title{
Features of the Cloud Base Height and Determining the Threshold of Relative Humidity over Southeast China
}

\author{
Yuzhi Liu *, Yuhan Tang, Shan Hua, Run Luo and Qingzhe Zhu
}

Key Laboratory for Semi-Arid Climate Change of the Ministry of Education, College of Atmospheric Sciences, Lanzhou University, Lanzhou 730000, China; tangyh14@lzu.edu.cn (Y.T.); huash15@lzu.edu.cn (S.H.); luor14@lzu.edu.cn (R.L.); zhuqzh16@lzu.edu.cn (Q.Z.)

* Correspondence: liuyzh@lzu.edu.cn; Tel.: +86-139-1991-5375

Received: 13 October 2019; Accepted: 3 December 2019; Published: 5 December 2019

\begin{abstract}
Clouds play a critical role in adjusting the global radiation budget and hydrological cycle; however, obtaining accurate information on the cloud base height $(\mathrm{CBH})$ is still challenging. In this study, based on Lidar and aircraft soundings, we investigated the features of the $\mathrm{CBH}$ and determined the thresholds of the environmental relative humidity ( $\mathrm{RH}$ ) corresponding to the observed CBHs over Southeast China from October 2017 to September 2018. During the observational period, the CBHs detected by Lidar/aircraft were commonly higher in cold months and lower in warm months; in the latter, $75.91 \%$ of the CBHs were below $2000 \mathrm{~m}$. Overall, the RHs at the cloud base were mainly distributed between 70 and $90 \%$ for the clouds lower than $1000 \mathrm{~m}$, in which the most concentrated RH was approximately $80 \%$. In addition, for the clouds with a cloud base higher than $1000 \mathrm{~m}$, the $\mathrm{RH}$ thresholds decreased dramatically with increasing $\mathrm{CBH}$, where the $\mathrm{RH}$ thresholds at cloud bases higher than $2000 \mathrm{~m}$ could be lower than $60 \%$. On average, the RH thresholds for determining the CBHs were the highest $(72.39 \%)$ and lowest $(63.56 \%)$ in the summer and winter, respectively, over Southeast China. Therefore, to determine the $\mathrm{CBH}$, a specific threshold of $\mathrm{RH}$ is needed. Although the time period covered by the collected $\mathrm{CBH}$ data from Lidar/aircraft is short, the above analyses can provide some verification and evidence for using the $\mathrm{RH}$ threshold to determine the $\mathrm{CBH}$.
\end{abstract}

Keywords: cloud base height; ground-based observations; relative humidity profile; threshold

\section{Introduction}

Clouds can adjust the Earth's energy budget and hydrological cycle through dynamic and thermal processes [1-3] and further drive the climate to change globally [4]. However, considerable uncertainties in cloud properties have been found [5], further contributing to errors in weather forecasting and climate prediction [6]. The immense uncertainties regarding clouds include optical [7-9], microphysical $[10,11]$, and geometrical $[12,13]$ features, the effects on the radiation budget [14], interactions with aerosols [15-21], and impacts on precipitation [22,23]. In particular, the cloud profile is poorly understood at present and remains a primary source of uncertainty in global weather and climate research [24].

The cloud base height $(\mathrm{CBH})$, which is an important parameter of the cloud vertical profile, largely determines the energy exchanges between the clouds and surface. Accordingly, determining the CBHs is extremely critical for weather forecasting and ensuring flight safety $[25,26]$. Currently, retrieving the $\mathrm{CBH}$ generally relies primarily on satellite and ground-based observations. Space-borne active satellite remote sensing (e.g., the cloud profile radar (CPR) mounted on CloudSat and the Cloud-Aerosol Lidar with Orthogonal Polarization (CALIOP) aboard Cloud-Aerosol Lidar and Infrared Satellite Observation 
(CALIPSO)) has allowed cloud profile information to be obtained globally [27-29]. Some studies have estimated the $\mathrm{CBH}$ by applying both satellite-derived cloud optical depth, cloud water path, and some additional parameterizations that connect cloud optical depth with cloud geometrical thickness [30,31]. Other methods have also been used to estimate the CBH [32-34]. For example, Liang et al. [35] estimated the CBH by combining measurements from CloudSat/CALIPSO and Moderate-resolution Imaging Spectroradiometer (MODIS) based on the International Satellite Cloud Climatology Project (ISCCP) cloud-type classification and a weighted algorithm; unfortunately, the calculation of the CBH is dependent on an assumption of the cloud water content [36]. However, a comparison with the ground-based active remote sensing of clouds revealed large uncertainties in the $\mathrm{CBH}$ from satellite observations [37]. Therefore, obtaining information on the $\mathrm{CBH}$ with high accuracy is urgent.

Compared with satellite observations, ground-based cloud observations can provide $\mathrm{CBH}$ measurements with higher accuracy [34]. Some retrievals of the CBH are based on Lidar instruments [33], ceilometers [38], radiosondes [39-42], and total-sky-imager (TSI) [43]. Long-term research on the $\mathrm{CBH}$ measurements by radiosondes and ceilometer has been ongoing such as an analysis of 25-year CBHs measured by ceilometer at the Arctic site [44]. Some inter-comparisons among ground-based instruments have been performed [45-49]. In addition, some methods for calculating the CBHs have been reported by some earlier studies. Chernykh and Eskridge [50] proposed a method for judging the position of clouds using the second derivative of temperature and relative humidity (RH) versus the height in the ground-based soundings. For a long time, good agreement between the $\mathrm{CBH}$ and the lifting condensation level (LCL) estimated from the surface layer air have been confirmed and applied [51-53]. On this basis, Romps [54] gave the dependence of LCL on the temperature and RH and the conditions for cloud formation at heights such as the lifting deposition level (LDL) and the lifting freezing level (LFL). Wang and Rossow [2] postulated that an RH threshold value of $84 \%$ could be used to determine the cloud base location based on rawinsonde data. Additionally, Zhang et al. [42] performed an uncertainty analysis on the sensitivity of the $\mathrm{CBH}$ to different $\mathrm{RH}$ thresholds $(83 \%, 84 \%$, and $85 \%$ ). To some degree, $\mathrm{RH}$ information at the cloud layer is significant in determining the CBHs from ground-based observations. Thus, an assessment of the RH threshold that can best determine the $\mathrm{CBH}$ is needed.

In this study, based on Lidar, pilot balloon, and aircraft soundings, the features of the $\mathrm{CBH}$ and the threshold of the environmental RH to determine the cloud base over Southeast China were investigated in detail. First, a comparison among the CBHs derived from three kinds of ground-based observations was performed. The observations with high accuracy were then selected as the reference. Next, combining the $\mathrm{RH}$ profiles from ERA-Interim data, the RH thresholds were calculated corresponding to the observed CBHs. Finally, the RH thresholds in different seasons for different $\mathrm{CBH}$ s were analyzed.

\section{Datasets and Methods}

\subsection{Ground-Based Observations}

At numerous sites throughout Southeast China (blue triangles in Figure 1), we performed observations with cloud Lidar (laser ceilometer), pilot balloon, and aircraft soundings from October 2017 to September 2018. The information on the sites is listed in Table 1.

We derived the cloud height using a cloud Lidar, whose emission source was a InGaAs $905 \mathrm{~nm}$ wavelength and $1.76 \mu \mathrm{J}$ pulse energy with a pulse repetition frequency of $1000 \mathrm{~Hz}$. The pulse duration was $45 \mathrm{~ns}$, and the beam divergence was less than $3 \mathrm{mrad}$. The detection range of cloud Lidar spans from $20 \mathrm{~m}$ to $7600 \mathrm{~m}$ with a vertical resolution of $3.8 \mathrm{~m}$ and a temporal resolution of 30 seconds. Lidar can scan the atmosphere with an elevation angle ranging from $-30^{\circ}$ to $30^{\circ}$ and an azimuth in the range of $0-240^{\circ}$. The details about the technical specifications of the cloud Lidar used in this study are shown in Table 2. The retrieved CBH data [55,56] at seven sites from October 2017 to September 2018 were used. 
Meanwhile, the $\mathrm{CBH}$ observations sounded by aircraft were also used in this study. The $\mathrm{CBH}$ detected by the aircraft soundings is obtained when the aircraft is flying upward through the cloud at the observational sites. When the aircraft enters the cloud, the pilot gives an altitude report for that moment, which is considered the height of the cloud base.

Additionally, a pilot balloon together with a GYR1 electronic optical wind theodolite was used to detect the $\mathrm{CBH}$. After releasing a pilot balloon with a fixed rise velocity $(\omega)$ from the surface, a theodolite telescope is used to track the balloon. When the balloon starts to enter the clouds, the angular coordinate (elevation angle and azimuth angle) can be recorded. Then, the duration from the time of releasing balloon to the time of entering the cloud $(t)$ can be calculated. Finally, the $\mathrm{CBH}$ can be estimated as the product of $\omega$ and $t$, that is, $C B H=\omega \times t$.

Table 1. Information on the observational sites for the cloud base height (CBH).

\begin{tabular}{cccccc}
\hline \multirow{2}{*}{ Site } & \multirow{2}{*}{ Location } & $\begin{array}{c}\text { Elevation (m; Above } \\
\text { Sea Level })\end{array}$ & \multicolumn{3}{c}{ Number of Samples } \\
\cline { 4 - 6 } & & 397 & Aircraft & Lidar & Pilot Balloon \\
\hline $\mathrm{A}$ & $\left(117^{\circ} \mathrm{E}, 25^{\circ} \mathrm{N}\right)$ & 13.8 & 58 & 2854 & 161 \\
\hline $\mathrm{B}$ & $\left(116^{\circ} \mathrm{E}, 23^{\circ} \mathrm{N}\right)$ & 16 & 60 & 300 & 168 \\
\hline $\mathrm{C}$ & $\left(115^{\circ} \mathrm{E}, 28^{\circ} \mathrm{N}\right)$ & 366.6 & 45 & 1748 & 182 \\
\hline $\mathrm{D}$ & $\left(120^{\circ} \mathrm{E}, 26^{\circ} \mathrm{N}\right)$ & 15.7 & 75 & 76 & 19 \\
\hline $\mathrm{E}$ & $\left(118^{\circ} \mathrm{E}, 34^{\circ} \mathrm{N}\right)$ & 4.1 & 28 & 177 & 23 \\
\hline $\mathrm{F}$ & $\left(120^{\circ} \mathrm{E}, 30^{\circ} \mathrm{N}\right)$ & 4.4 & 50 & 47 & 24 \\
\hline $\mathrm{G}$ & $\left(121^{\circ} \mathrm{E}, 31^{\circ} \mathrm{N}\right)$ & & & &
\end{tabular}

Table 2. Technical specifications of the cloud Lidar.

\begin{tabular}{cc}
\hline Parameter Name & Parameter Value \\
\hline Laser & InGaAs (a semiconductor laser) \\
Wavelength & $905 \pm 10 \mathrm{~nm}$ \\
Single laser pulse energy & $\leq 20 \mu \mathrm{J}$ \\
Pulse width & $45 \mathrm{~ns} \pm 10 \mathrm{~ns}$ \\
Scattering angle of laser beam & $\leq 3 \mathrm{mrad}$ \\
Pulse repetition frequency & $1 \mathrm{kHz} \pm 15 \%$ \\
Effective aperture of the optical system & $102 \mathrm{~mm}$ \\
Interferometric filter & $910 \pm 15 \mathrm{~nm}$ \\
\hline
\end{tabular}

\subsection{Clouds and the Earth's Radiant Energy System (CERES)}

Cloud fraction and cloud base pressure data (SYN dataset) from October 2017 to September 2018 derived from Clouds and the Earth's Radiant Energy System (CERES) mounted on the Aqua satellite were used in this paper. The temporal and spatial resolutions of these CERES data are hourly and $1^{\circ} \times 1^{\circ}$, respectively [57]. Here, the cloud base pressure (CBP) data provided by CERES were used for an intercomparison with the above-mentioned ground-based observations. According to the locations of the ground-based sites and observational time, the CBPs from the CERES data corresponding to the site location were extracted for a comparison with the calculated CBPs from CBHs.

\subsection{ERA-Interim Reanalysis Data}

ERA-Interim data released by the European Centre for Medium-Range Weather Forecasts (ECMWF) can provide assimilated reanalysis data four times a day (the temporal resolution is $6 \mathrm{~h}$ ). In this study, $\mathrm{RH}$ profiles with a horizontal spatial resolution of $0.25^{\circ} \times 0.25^{\circ}$ were used. In the vertical direction, the $\mathrm{RH}$ profiles had 37 layers from $1000 \mathrm{hPa}$ to $1 \mathrm{hPa}$. The RHs employed in this study were extracted from the ERA-Interim data at 20 levels (from 1000 to $300 \mathrm{hPa}$ ) with a temporal resolution of 6 hours $(0: 00,6: 00,12: 00$, and 18:00 UTC) [58]. 


\subsection{Method of Conversion from Cloud Base Height (CBH) to Cloud Base Pressure (CBP)}

In the cloud base datasets, the cloud base information from the CERES data is scaled by pressure (unit: $\mathrm{hPa}$ ), while the $\mathrm{CBHs}$ detected by cloud Lidar and aircraft are measured as the geometric height (unit: $\mathrm{m}$ ). To compare the ground-based measurement, a conversion from the CBH to the CBP is needed. Here, according to the pressure-height formula of polytropic atmosphere [59], CBP can be calculated from $\mathrm{CBH}$.

$$
\begin{gathered}
C B P=P_{S F} \times\left[1-\frac{\Gamma \times C B H}{T_{v_{-} C B}}\right]^{\frac{g}{R \Gamma}} \\
T_{v_{-} S F}=\left(1+0.608 q_{S F}\right) T_{S F} \\
T_{v_{-} C B}=T_{v_{-} S F}-\Gamma \times C B H
\end{gathered}
$$

where $g$ is the acceleration of gravity, here, it takes as $9.8 \mathrm{~m} / \mathrm{s}$; $R$ is the gas constant, $R=287.05 \mathrm{~J} / \mathrm{kg} / \mathrm{K}$; and $\Gamma$ is the temperature lapse rate, taken as $6.5 \mathrm{~K} / \mathrm{km}$ here. $P_{S F}$ is the atmospheric pressure at the surface. Based on Equation (2), the virtual air temperature at $2 \mathrm{~m}\left(T_{V_{-} S F}\right)$ can be calculated from specific humidity $\left(q_{S F}\right)$ based on ERA-Interim data and observed temperature at the ground-based sites. The virtual air temperature at the cloud base $\left(T_{v_{-} C B}\right)$ can be further calculated by Equation (3). Finally, based on the above formulas, the CBP can be calculated.

Based on the RH profiles from the ERA reanalysis data, the RH values at the cloud base can be extracted according to the CBPs calculated according to the above method, and the extracted RH value is regarded as the $\mathrm{RH}$ threshold at the cloud base.

\section{Results}

Figure 1 shows the distribution of observational sites (blue triangles) and the annual mean cloud fraction derived from CERES product in China from October 2017 to September 2018. As shown in Figure 1, during the above period, a high cloud fraction was distributed across South China with a value of approximately $80 \%$. Low-value areas were located in North China, especially Inner Mongolia, with a minimum cloud fraction of $37.35 \%$. Among the seven sites (blue triangles in Figure 1) involved in this study, the annual mean cloud fractions over sites $C$ and $D$ were approximately $70 \%$, while those over sites A, B, and F were approximately 65\%; however, the lowest cloud fraction (below 60\%) was found over site $\mathrm{E}$.

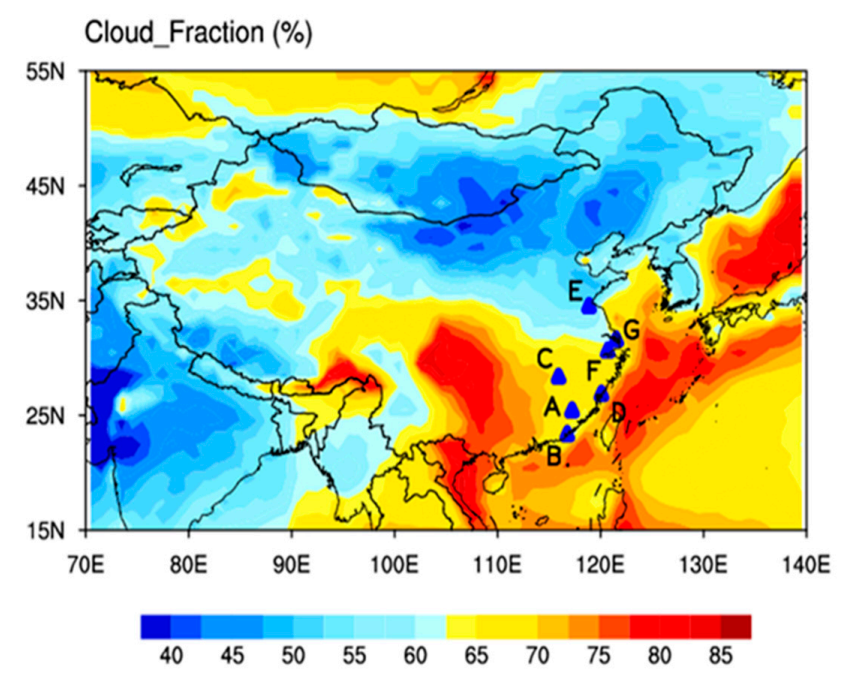

Figure 1. Distribution of the annual mean cloud fraction (unit: \%) derived from Clouds and the Earth's Radiant Energy System (CERES) product in the period from October 2017 to September 2018 and the distribution of observational sites for the cloud base height $(\mathrm{CBH})$ in Southeast China. The blue triangles denote the ground-based observational sites for the $\mathrm{CBH}$. 


\subsection{Intercomparison among the CBHs from Multi-Sourced Data}

Compared with satellite measurements, ground-based cloud observations can provide $\mathrm{CBH}$ measurements with higher accuracy and a continuous temporal coverage. Moreover, aircraft soundings can provide more accurate $\mathrm{CBH}$ information than ground-based observations. Therefore, aircraft-sounded $\mathrm{CBH}$ sere considered to be an accurate reference in this study. In the subsequent analyses, the CBHs derived from two kinds of ground-based observations, pilot balloon and cloud Lidar, and from aircraft soundings during the period from October 2017 to September 2018 were analyzed at each of the seven sites (details as shown in Figure 1 and Table 1) to give the features of the $\mathrm{CBH}$ over those areas. Figure 2 shows a comparison of the CBHs sounded by aircraft with those detected by cloud Lidar and pilot balloon during the observational period. The results show that the correlation coefficient between the aircraft-sounded and Lidar-observed CBH was 0.86, which indicates good consistency between the CBHs detected by the cloud Lidar and those sounded by the aircraft. In addition, most of the $\mathrm{CBH}$ detected by the Lidar were somewhat higher than those sounded by aircraft when the cloud bases were lower than $2000 \mathrm{~m}$. However, when the cloud bases were higher than $2000 \mathrm{~m}$, most of the Lidar-observed CBHs were slightly lower than the aircraft-soundings. Additionally, comparing the results detected by the pilot balloon with the CBHs sounded by aircraft, most of the CBHs sounded by the former were significantly higher than those sounded by the latter; the correlation coefficient was 0.65 . Thus, the $\mathrm{CBH}$ data detected by both Lidar and aircraft were regarded as accurate values. In the following analyses, these two sets of data were complementary and used in conjunction to analyze the features of the CBH over Southeast China.

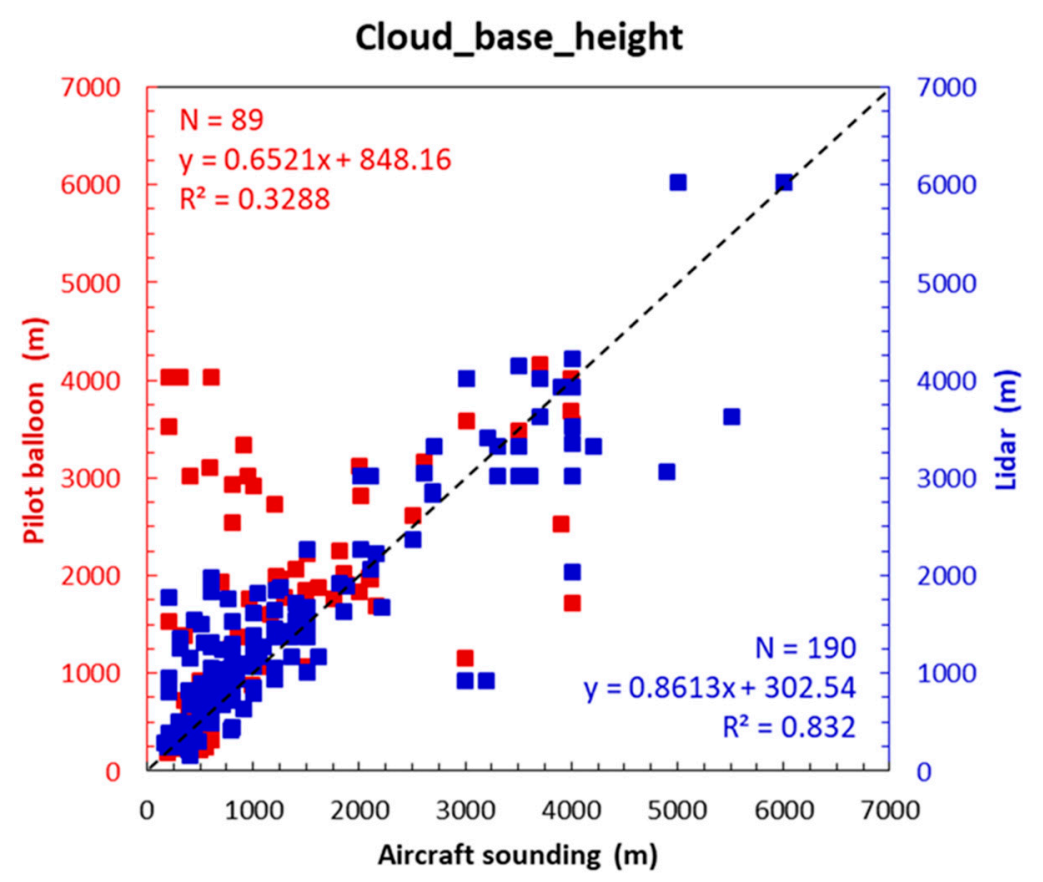

Figure 2. Scatter-grams of the Lidar/pilot-balloon observed and aircraft sounded CBHs at sites in Southeast China. The red and blue squares denote the CBHs from the pilot balloon and cloud Lidar, respectively.

\subsection{Features of the CBH over Southeast China}

Based on the $\mathrm{CBH}$ samples detected by the cloud Lidar and aircraft, the seasonal variations of the CBH during the period from October 2017 to September 2018 at seven sites were analyzed, as shown in Figure 3, 75.91\% of the CBH values at the seven sites were primarily below $2000 \mathrm{~m}$. Overall, the $\mathrm{CBH}$ in the summer were consistently lower than those in the other seasons at most of the sites except for site A. In addition, the summer CBHs were below $1000 \mathrm{~m}$ at sites D, E, and G, which are located 
along the oceanic coast. In this sense, at site $\mathrm{C}$, which is farther from the ocean than the other sites, the seasonal variation of the $\mathrm{CBH}$ is relatively small throughout the whole year. Therefore, at sites near the ocean, monsoon systems could affect the $\mathrm{CBH}$, which may be the reason for the seasonal $\mathrm{CBH}$ discrepancies among the different sites. Here, the error bars reflect the standard errors based on the means of the $\mathrm{CBH}$ samples at the seven sites. The standard errors at the sites are small, except for sites $\mathrm{E}$ and $\mathrm{F}$, which indicates the reliability of the statistical results with large sample sizes.

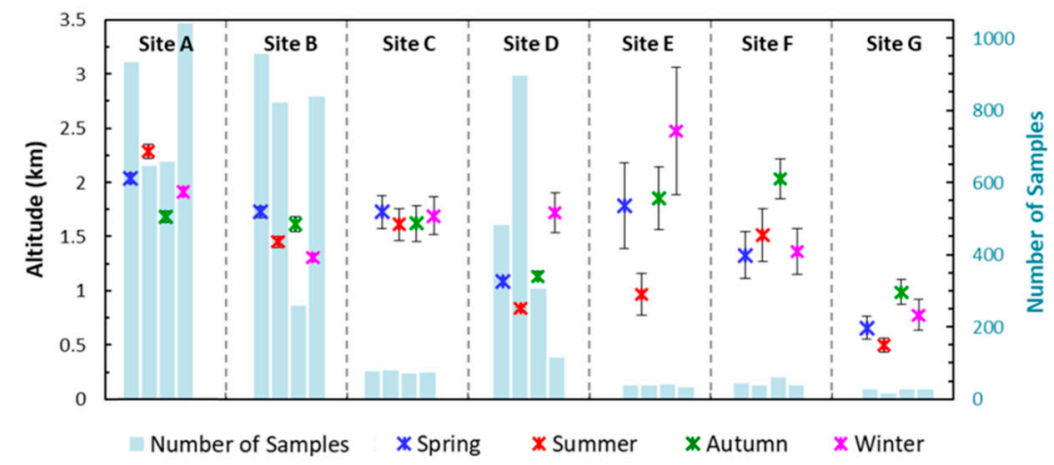

Figure 3. Seasonal variation of the mean $\mathrm{CBH}$ detected by cloud Lidar and aircraft during the period from October 2017 to September 2018 at seven ground-based sites. The light cyan bar represents the number of samples at each site in four seasons. Error bars represent the confidence levels of the mean values, assuming independent data. Errors are calculated as $\mathrm{s} /(n-2)^{\frac{1}{2}}$, where $n$ is the sample number of $\mathrm{CBH}$ measurements within the season and $s$ is the standard deviation.

Furthermore, the monthly and diurnal variations of the $\mathrm{CBH}$ were similarly analyzed, as illustrated in Figure 4. Due to the absence of records at some sites where observations are performed only at certain times of day, fewer sites provided diurnal variation information (Figure $4 \mathrm{~b}$ ) than sites that provide monthly variation information (Figure 4a). Relative to the average $\mathrm{CBHs}$ at all sites (black line in Figure 4a), the lower CBHs were found in June-August, while the higher CBHs occur in February and April. Overall, most of the CBHs (75.91\%) observed at seven sites were below $2000 \mathrm{~m}$; in addition, the higher $\mathrm{CBHs}$ appeared in cold months, while the lower ones occurred in warmer months. Specifically, as shown in Figure 4a, the average CBHs over site A in most months (January, March, and May-August) were higher values relatively, which was also reflected by the diurnal variation of the $\mathrm{CBH}$ (Figure $4 \mathrm{~b}$ ). Meanwhile, for the whole year, the monthly mean CBHs over site $\mathrm{G}$ presented the lowest values (below $1000 \mathrm{~m}$ ) among the seven sites, which is in agreement with the seasonal mean results in Figure 3. As shown in Figure 4b, overall, the mean values of the CBHs at sites A and B (green line in Figure $4 \mathrm{~b}$ ) were lower in the daytime than the nocturnal ones. Moreover, it was found that the CBHs over site B were much lower than those at site A, especially in the daytime (from 06:00 to 18:00). This phenomenon may be related to the fact that site B is located closer to the ocean than site A (as shown in Figure 1), as the abundance of water vapor from the ocean is beneficial to the formation of water clouds over site B. 

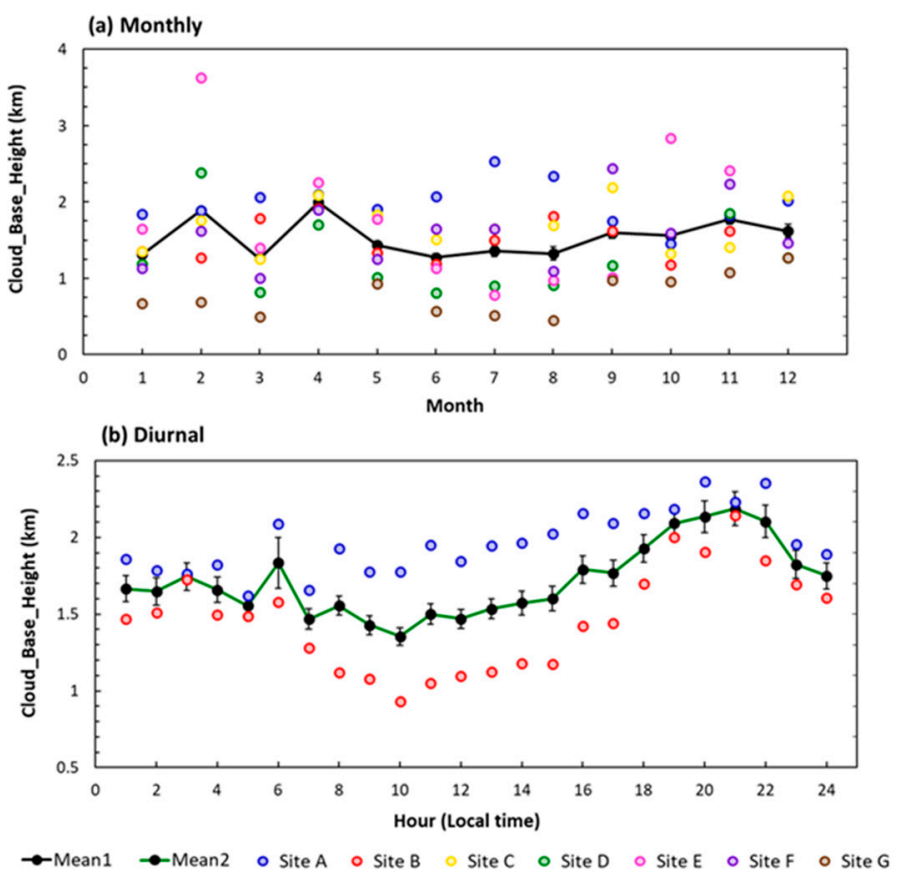

Figure 4. (a) Monthly and (b) diurnal variations of the CBH during the period from October 2017 to September 2018. Black line in (a) represents the average CBH at all sites. Green line in (b) denotes the average $\mathrm{CBH}$ at sites A and B. Error bars represent the confidence levels of the mean values, assuming independent data. Errors were calculated as $s /(n-2)^{\frac{1}{2}}$, where $n$ is the sample number of $\mathrm{CBH}$ measurements within the season and $s$ is the standard deviation.

\subsection{Features of the Relative Humidity (RH) Threshold for Determining the CBH over Southeast China}

According to Wang et al. [2], the CBH can be determined by the RH, and an $\mathrm{RH}$ of $84 \%$ was used as a threshold to determine the cloud base location. However, the scarcity of the sounding data limited an in-depth verification of determining the $\mathrm{CBH}$ by an $\mathrm{RH}$ threshold. Based on the above $\mathrm{CBH}$ data detected by cloud Lidar and aircraft, features of the RH thresholds used to determine the CBHs over these observational sites were investigated in the following analysis. The RH profiles derived from ERA reanalysis data together with observed surface air temperature and pressure at the ground-based sites were used to convert $\mathrm{CBH}$ to $\mathrm{CBP}$.

Based on the method described in Section 2.4, a conversion from the CBH in meters to the CBP in $\mathrm{hPa}$ was performed. The calculated pressures at the cloud bases were compared with those retrieved from CERES observations, as shown in Figure 5. The time series and a comparison of the CBPs derived from the CERES dataset with the CBPs calculated from ground-based observations are given in Figure 5a. The red and blue lines represent the CBPs obtained from CERES observations and those converted from the Lidar/aircraft measurements, respectively. As shown in Figure 5a, the CBPs from the CERES product were consistently smaller (corresponding higher cloud base) than those calculated from the Lidar/aircraft measurements during a large time period; the averaged CBPs from the CERES product and Lidar/aircraft measurements during the period from October 2017 to September 2018 were $806.81 \mathrm{hPa}$ and $860.67 \mathrm{hPa}$, respectively. Here, the CBH measurements obtained by Lidar/aircraft were relatively accurate. In this sense, the pressures at the cloud bases observed by CERES could overestimate the CBHs over these sites, which relates to the limited detection ability of passive satellite remote sensing for the cloud base location. Furthermore, according to the geometric heights of the cloud bases measured by Lidar/aircraft, the CBPs obtained from the CERES product were compared with those calculated from the Lidar/aircraft measurements, as shown in Figure $5 \mathrm{~b}$. For clouds higher than $1100 \mathrm{~m}$, the CBPs observed by CERES and measured by Lidar/aircraft showed great agreement. However, as shown in Figure 5b, the CERES observations slightly overestimated the cloud 
base locations in reference to the detection results of Lidar/aircraft, especially for clouds lower than $1100 \mathrm{~m}$. Furthermore, the correlation of CBPs between CERES observations with those calculated by Lidar/aircraft measurements was performed (Figure 5c,d). For the samples of all CBHs (represented by green in Figure 5c), CBPs observed by CERES were significantly smaller than those from Lidar/aircraft measurements (especially for the clouds lower than $1100 \mathrm{~m}$ ), with a correlation coefficient of 0.790 (significant above the 99\% confidence level). However, it was found that the correlation coefficient of the CBPs between CERES observations and the ones calculated from Lidar/aircraft measurements for the clouds higher than $1100 \mathrm{~m}$ (represented by yellow in Figure 5d) was 0.832 (significant above the 99\% confidence level), which indicates the great agreement of the CERES observations with calculations from Lidar/aircraft measurements.
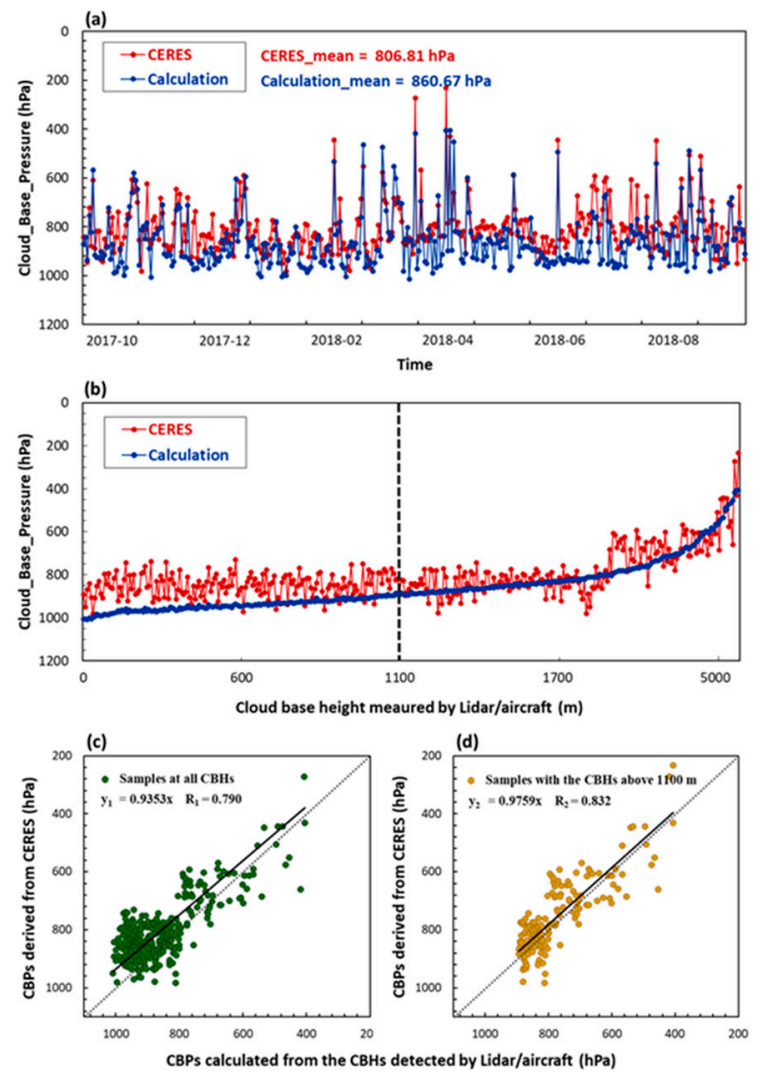

Figure 5. (a) Time series and (b) comparison of the CBPs derived from CERES observations with those calculated from the CBHs detected by Lidar/aircraft at site B during the period from October 2017 to September 2018. Correlation between the CBPs derived from CERES observations with those calculated from Lidar/aircraft measurements for samples of (c) all CBHs and (d) CBHs above $1100 \mathrm{~m}$ at site B during the period from October 2017 to September 2018.

Furthermore, based on the CBPs calculated from the CBHs detected by Lidar/aircraft, the RH values at the cloud base were further extracted from the ERA data. In a sense, the extracted RH values at the cloud base can be regarded as the thresholds for determining the CBHs. Figure 6 shows the correlation between the RHs at the cloud base and the CBHs detected by Lidar/aircraft at the seven sites during the period from October 2017 to September 2018. Overall, most of the RH values at the cloud base ranged from approximately 70 to $90 \%$, where the $\mathrm{CBHs}$ were below $2000 \mathrm{~m}$. As the $\mathrm{CBH}$ increased from $2000 \mathrm{~m}$, the RH threshold began to decrease to smaller than $60 \%$. As shown in Figure 6, when the CBH was lower than $1000 \mathrm{~m}$, it corresponded to a stable RH threshold of approximately $80 \%$. When the $\mathrm{CBH}$ ranged from 1000 to $2000 \mathrm{~m}$, the $\mathrm{RH}$ threshold was below $80 \%$ and decreased with increasing CBH. However, when the CBH was higher than $2000 \mathrm{~m}$, the RH threshold decreased dramatically with increasing $\mathrm{CBH}$. Additionally, it was found that the samples showed a large scatter 
and were sparsely distributed in the region with a RH threshold below $60 \%$. Here, the raw values of the RH calculated from the detected CBHs and the RH profiles from the ERA data are illustrated in Figure 6, which presents an uncertainty induced by the RH profiles provided by the ERA data, especially for the clouds at middle and high levels. However, the phenomenon of a relatively low $\mathrm{RH}$ threshold for determining the CBHs for relatively high clouds was revealed.

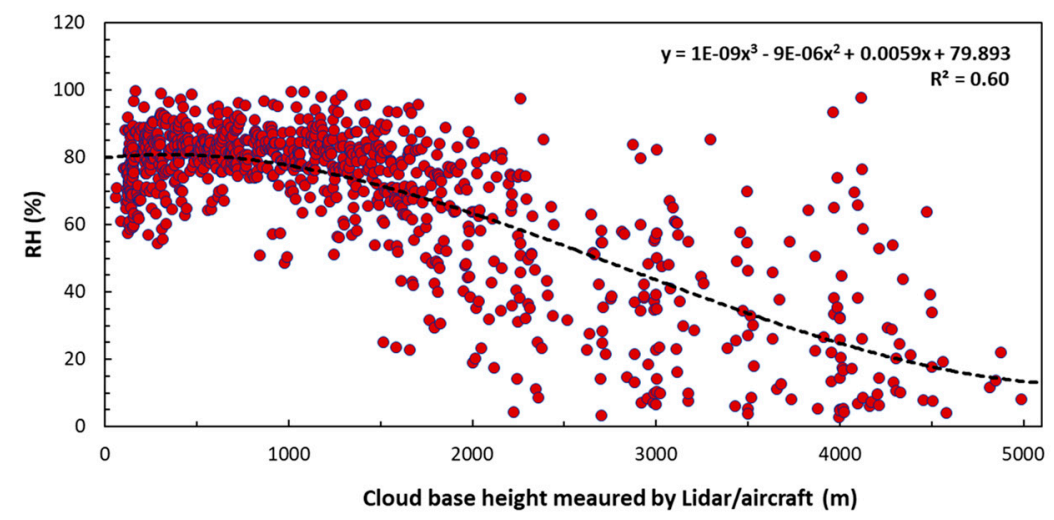

Figure 6. Correlation between the RHs at the cloud base and the CBHs detected by Lidar/aircraft at all sites during the period from October 2017 to September 2018. The black dashed line denotes the fitting result with a cubic polynomial.

The sample percentages for each RH threshold bin were statistically calculated, as shown in Figure 7. For the clouds with base heights ranging from 0 to $1000 \mathrm{~m}$, the samples were dominantly distributed from 50 to $100 \%$, where the maximum percentage of samples $(47.43 \%)$ was in the bin ranging from 80 to $90 \%$. For the $\mathrm{CBHs}$ ranging from 1000 to $2000 \mathrm{~m}$, the samples were mainly in the RH bins from 20 to $100 \%$, where the maximum percentage of samples $(31.01 \%)$ was distributed in the bin ranging from 80 to $90 \%$. However, for the clouds with base heights exceeding $3000 \mathrm{~m}$, the samples were mainly distributed in the bins with RHs lower than $50 \%$, where the highest sample percentage (49.12\%) was distributed in the RH bin below 20\% for CBHs larger than $4000 \mathrm{~m}$.

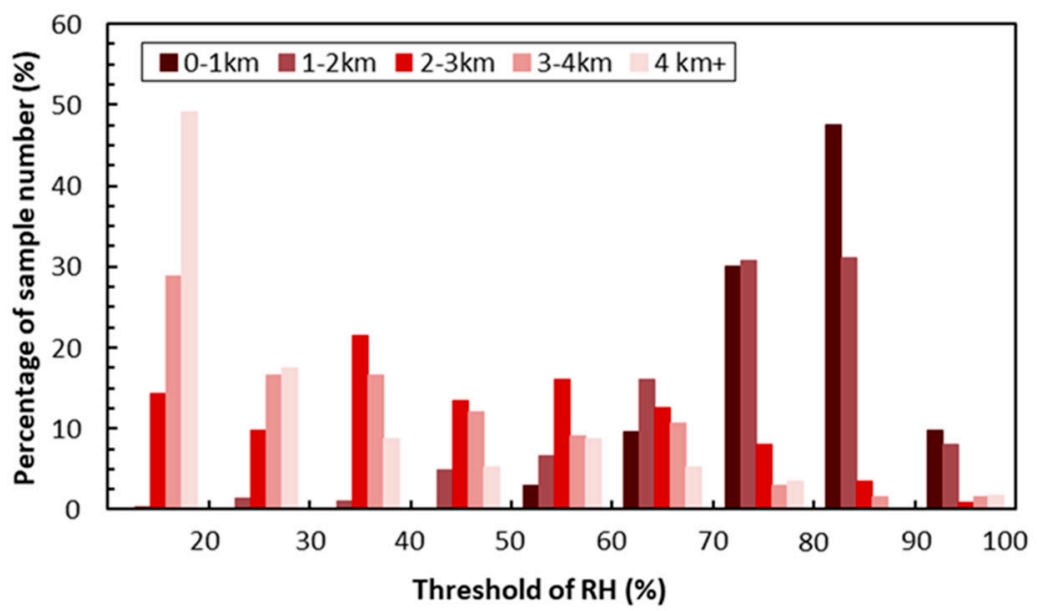

Figure 7. Distribution of the sample number percentage (unit: \%) in each RH threshold bin for various CBHs measured by Lidar/aircraft at sites B, C, and F during the period from October 2017 to September 2018.

Among the seven sites, the $\mathrm{CBH}$ data detected by Lidar/aircraft at sites $\mathrm{B}, \mathrm{C}$, and $\mathrm{F}$ had better temporal continuity than the $\mathrm{CBH}$ data at the other sites during the period from October 2017 to September 2018. Here, an analysis on the RH thresholds for determining the CBHs was performed 
based on the above three sites (B, C, and F), as shown in Figure 8 (details are in Table 3). As revealed above, the $\mathrm{RH}$ thresholds at the three sites ranged approximately from 70 to $90 \%$, where the CBHs were below $2000 \mathrm{~m}$ (as shown in the box in Figure 8); the means of the RH thresholds were approximately $80 \%$ except for site F (as shown in black squares in Figure 8). As the CBH increased from $2000 \mathrm{~m}$, the $\mathrm{RH}$ threshold began to decrease, especially at site C. Overall, the average $\mathrm{RH}$ threshold decreased with the increase in $\mathrm{CBH}$. The maximum $\mathrm{RH}$ threshold (with a mean of $79.88 \%$ for these three sites) was found for the clouds with base heights ranging from 0 to $1000 \mathrm{~m}$. Then, with an increase in the $\mathrm{CBH}$ above $1000 \mathrm{~m}$, the average $\mathrm{RH}$ threshold decreased and reached the minimum (28.92\%) for the CBHs larger than $4000 \mathrm{~m}$. As shown in Figure 8, a significant difference among the $\mathrm{RH}$ thresholds for determining the CBHs among the above three sites was mainly observed for the clouds with base heights exceeding $4000 \mathrm{~m}$.

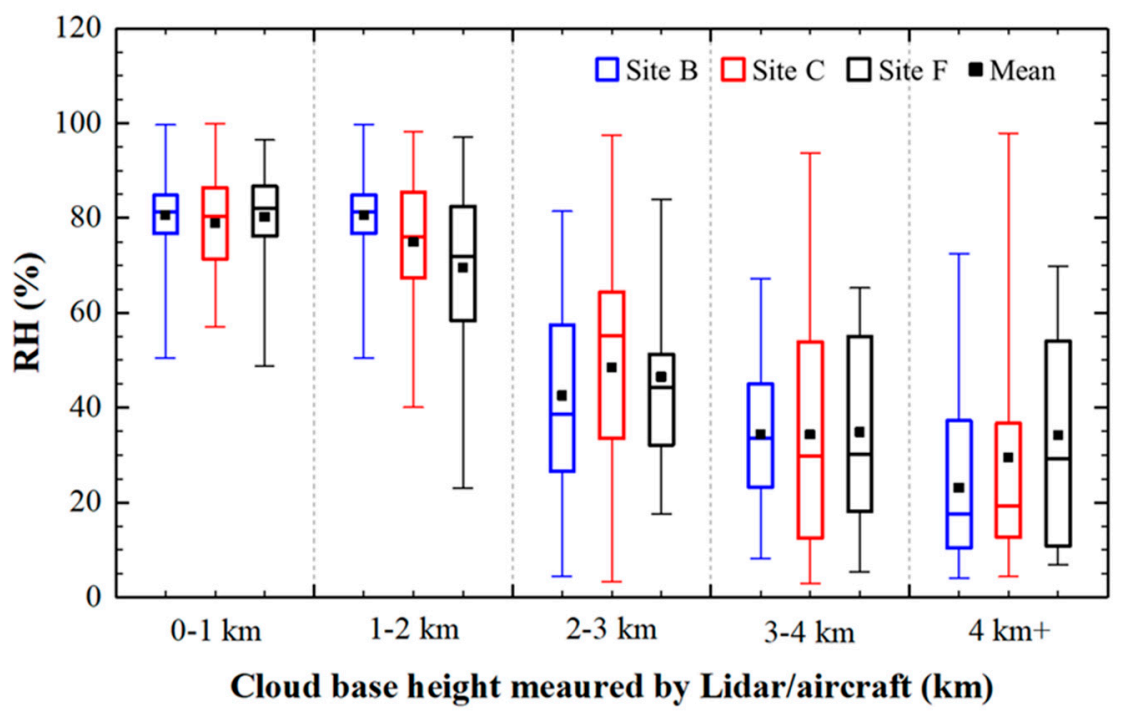

Figure 8. Statistics on the RH threshold for the clouds with different height at sites B, C, and F during the period from October 2017 to September 2018. Whiskers cover the range of RH thresholds. The upper, middle, and lower lines of the box correspond to the first, second, and third quartiles (the 75th, 50th, and 25th percentiles). Black squares denote the means of RH threshold.

Table 3. Characteristics of the relative humidity thresholds of the $\mathrm{CBH}$ (unit: \%).

\begin{tabular}{cccccc}
\hline $\begin{array}{c}\text { Altitude of the } \\
\text { Cloud Base }\end{array}$ & Site B & Site C & Site F & $\begin{array}{c}\text { Number of } \\
\text { Samples }\end{array}$ & $\begin{array}{c}\text { Mean } \\
\text { Threshold }\end{array}$ \\
\hline$\leq 1 \mathrm{~km}$ & 80.54 & 78.90 & 80.21 & 415 & 79.88 \\
$1-2 \mathrm{~km}$ & 76.04 & 74.91 & 72.44 & 337 & 74.46 \\
$2-3 \mathrm{~km}$ & 42.56 & 48.50 & 46.51 & 110 & 45.86 \\
$3-4 \mathrm{~km}$ & 34.36 & 34.32 & 34.84 & 64 & 34.51 \\
$>4 \mathrm{~km}$ & 23.11 & 29.53 & 34.12 & 56 & 28.92 \\
\hline
\end{tabular}

As illustrated above, overall, the RH threshold decreased with an increase in the $\mathrm{CBH}$, especially when the CBH was higher than $2000 \mathrm{~m}$. Furthermore, the seasonal variation of the RH thresholds for determining the CBHs during the period from October 2017 to September 2018 was analyzed. The sample percentages for each RH threshold bin in different seasons are shown in Figure 9. For all seasons, the highest samples were dominantly distributed in the bin from 80 to $90 \%$, where the maximum percentage was $40.55 \%$ in the summer. This finding is in agreement with the results in Figure 4 . In another sense, for the RH threshold bins larger than 70\%, most of the samples were obtained in spring and summer, while the fewest samples were obtained in autumn. However, for the RH threshold bins ranging from 30 to $70 \%$, the samples were mainly collected in the autumn. For the $\mathrm{RH}$ threshold bins below 30\%, most of the samples were detected in the spring (7.81\%) and winter $(11.93 \%)$. Furthermore, 
the $\mathrm{RH}$ thresholds for determining the $\mathrm{CBHs}$ at sites $\mathrm{B}, \mathrm{C}$, and $\mathrm{F}$ in different seasons were statistically calculated, as shown in Figure 10 (details are in Table 4). This figure shows that the maximum $\mathrm{RH}$ threshold (with a mean of $72.39 \%$ for sites B, C, and F) was found in the summer, which is consistent with the results shown in Figure 9. Moreover, the average RH thresholds in the spring, autumn, and winter were $65.25 \%, 66.91 \%$, and $63.56 \%$, respectively. Overall, the RHs at site B indicated slightly higher thresholds than the RHs at sites $\mathrm{C}$ and $\mathrm{F}$ for all seasons. Furthermore, the RH threshold at site $\mathrm{C}$ showed obvious variation in the autumn and winter seasons (as shown in the box in Figure 10), which may be related to the water vapor condition over there.

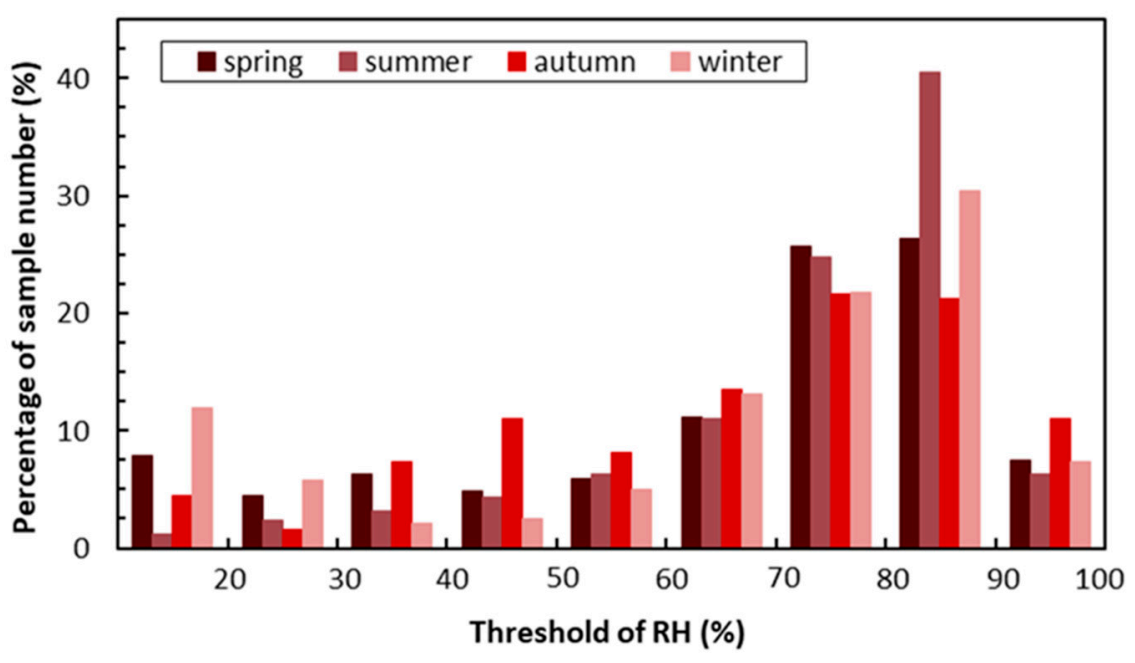

Figure 9. Seasonal distribution of the sample number percentage (unit: \%) in each RH threshold bin for various CBHs measured by Lidar/aircraft at sites B, C, and F during the period from October 2017 to September 2018.

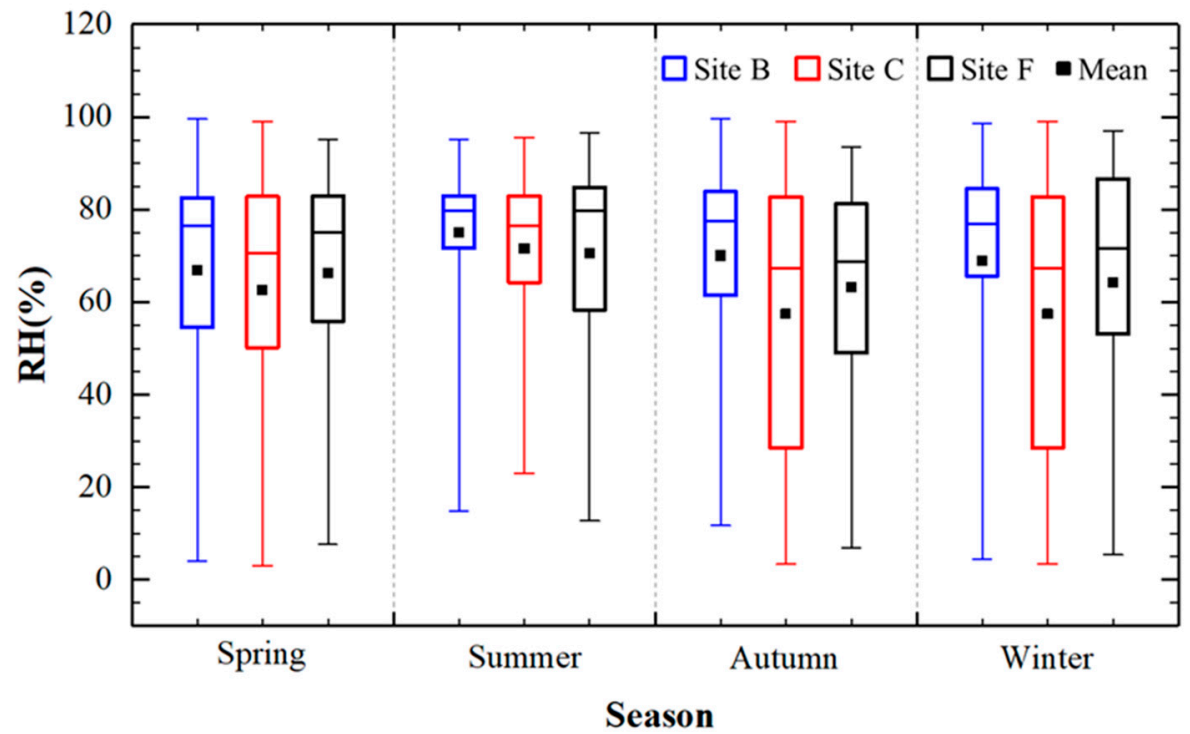

Figure 10. Seasonal statistics on the RH threshold for determining the CBHs at sites $\mathrm{B}, \mathrm{C}$, and F during the period from October 2017 to September 2018. Whiskers cover the range of RH thresholds. The upper, middle, and lower lines of the box correspond to the first, second, and third quartiles (the 75th, 50th, and 25th percentiles). Black squares denote the means of RH threshold. 
Table 4. Seasonal average of the relative humidity thresholds of the $\mathrm{CBH}$ (unit: \%).

\begin{tabular}{cccccc}
\hline Seasons & Site B & Site C & Site F & $\begin{array}{c}\text { Number of } \\
\text { Samples }\end{array}$ & $\begin{array}{c}\text { Mean } \\
\text { Threshold }\end{array}$ \\
\hline Spring & 66.89 & 62.56 & 66.31 & 269 & 65.25 \\
Summer & 75.09 & 71.58 & 70.51 & 254 & 72.39 \\
Autumn & 70.52 & 64.88 & 65.32 & 262 & 66.91 \\
Winter & 68.93 & 57.46 & 64.28 & 243 & 63.56 \\
\hline
\end{tabular}

\section{Conclusions}

CBH data detected by Lidar, pilot balloon, and aircraft over Southeast China during the period from October 2017 to September 2018 were analyzed in this study. A comparison among the CBHs detected by Lidar, pilot balloon, and aircraft at seven ground-based sites showed that the CBHs observed by Lidar and aircraft were more consistent with a correlation coefficient of 0.86 , and thus, the data from Lidar and aircraft were regarded as an accurate reference. During the observational period, the CBHs were higher in the cold months and lower in the warm months; in the latter, most of the CBHs were primarily below $2000 \mathrm{~m}$.

Combined with the RH profiles provided by ERA-Interim data, the RH thresholds were calculated corresponding to the observed CBHs. Overall, the RH threshold was stable at approximately $80 \%$ when the $\mathrm{CBH}$ was lower than $1000 \mathrm{~m}$; however, with the increase in $\mathrm{CBH}$, the $\mathrm{RH}$ threshold began to decrease dramatically, even below $60 \%$, as the $\mathrm{CBH}$ was larger than $2000 \mathrm{~m}$. Seasonally, the maximum $(72.39 \%)$ and minimum (63.56\%) RH thresholds were found in the summer and winter, respectively. In addition, the average $\mathrm{RH}$ thresholds in the spring and autumn were $65.25 \%$ and $66.91 \%$, respectively.

Although some interesting results were found in this study, some uncertainties in the RH threshold calculation based on the profiles from the ERA reanalysis data may be present in the analyses. A huge uncertainty may be induced by the establishment of humidity profiles from ERA reanalysis data. As pointed out by Chernykh and Aldukhov [60], the profile resolution of the reanalysis data could produce some errors in the gradient calculation that forms part of the cloud base determination. Second, the calculation of the $\mathrm{CBH}$, according to the pressure-height formula of polytropic atmosphere, could introduce inevitable errors. Additionally, the RH thresholds for determining the CBHs varied dramatically with the time and $\mathrm{CBH}$, and thus, using an average $\mathrm{RH}$ threshold to determine the $\mathrm{CBH}$ may conceal some accurate cloud height information. In the future, by combining ground-based and satellite-based observations of the $\mathrm{CBH}$, an artificial neural network method can be used to obtain more accurate $\mathrm{CBHs}$, which will be significantly beneficial to weather forecasting.

Author Contributions: Y.L. designed the paper; Y.T. wrote the original draft; Y.L. and Y.T. wrote, reviewed, and edited; S.H. and Q.Z. helped in data processing; Y.L., Y.T., and R.L. reviewed and revised the paper.

Funding: This research was funded by the Strategic Priority Research Program of the Chinese Academy of Sciences (Grant No. XDA2006010301) and was jointly supported by the National Natural Science Foundation of China (91744311 and 91737101).

Acknowledgments: We acknowledge the CERES (https://ceres.larc.nasa.gov/) and ECMWF (https://www.ecmwf. int/en/forecasts/datasets/reanalysis-datasets/era-interim) science teams for providing excellent and accessible data products that made this study possible. We are also grateful to the ground-based observations from the numerous sites.

Conflicts of Interest: The authors declare no conflicts of interest.

\section{References}

1. Ramanathan, V.; Cess, R.D.; Harrison, E.F.; Minnis, P.; Barkstrom, B.R.; Ahmad, E.; Hartmann, D. Cloud-radiative forcing and Climate: Results from the earth radiation budget experiment. Science 1989, 243, 57-63. [CrossRef]

2. Wang, J.H.; Rossow, W.B. Determination of cloud vertical structure from upper-air observations. J. Appl. Meteor. 1995, 34, 2243-2258. [CrossRef] 
3. Sun, B.; Groisman, P.Y. Cloudiness variations over the former Soviet Union. Int. J. Climatol. 2000, 20, 1097-1111. [CrossRef]

4. Naud, C.M.; Muller, J.P.; Clothiaux, E.E. Comparison between active sensor and radiosonde cloud boundaries over the ARM Southern Great Plains Site. J. Geophys. Res. 2003, 108, 1-12. [CrossRef]

5. Houghton, J.T.; Ding, Y.; Griggs, D.J.; Noguer, M.; van der Linden, P.J.; Dai, X.; Maskell, K.; Johnson, C.A. Climate Change 2001: The Scientific Basis; Cambridge University Press: New York, NY, USA, 2001; pp. 1-421.

6. Li, Z.Q.; William, W.K.; Ramanathan, V.; Wu, G.X.; Ding, Y.H.; Madakshira, G.M.; Liu, J.; Qian, Y.F.; Li, J.P.; Zhou, T.J.; et al. Aerosol and Monsoon Climate Interactions over Asia. Rev. Geophys. 2016, 54, 866-929. [CrossRef]

7. Shang, H.; Letu, H.; Nakajima, T.Y.; Wang, Z.; Ma, R.; Wang, T.; Lei, Y.; Ji, D.; Li, J. Diurnal cycle and seasonal variation of cloud cover over the Tibetan Plateau as determined from Himawari-8 new-generation geostationary satellite data. Sci. Rep. 2018, 8, 1105. [CrossRef] [PubMed]

8. Letu, H.; Nagao, T.M.; Nakajima, T.Y.; Riedi, J.; Ishimoto, H.; Baran, A.J.; Shang, H.; Sekiguchi, M.; Kikuchi, M. Ice cloud properties from Himawari-8/AHI next-generation geostationary satellite: Capability of the AHI to monitor the DC cloud generation process. IEEE Trans. Geosci. Remote. Sens. 2019, 57, 3229-3239. [CrossRef]

9. Liu, Y.; Hua, S.; Jia, R.; Huang, J. Effect of aerosols on the ice cloud properties over the Tibetan Plateau. J. Geophys. Res. Atmos. 2019, 124, 9594-9608. [CrossRef]

10. Huang, J.; Minnis, P.; Lin, B.; Yi, Y.H.; Fan, T.F.; Sun, S.M.; Ayers, J.K. Determination of ice water path in ice-over-water cloud systems using combined MODIS and AMSR-E measurements. Geophys. Res. Lett. 2006, 33, L21801. [CrossRef]

11. Li, J.; Jian, B.; Huang, J.P.; Hu, Y.; Zhao, C.; Kawamoto, K.; Liao, S.; Wu, M. Long-term variation of cloud droplet number concentrations from space-based Lidar. Remote. Sens. Environ. 2018, 213, 144-161. [CrossRef]

12. Letu, H.; Nagao, T.M.; Nakajima, T.Y.; Matsumae, Y. Method for validating cloud mask obtained from satellite measurements using ground-based sky camera. Appl. Opt. 2014, 53, 7523-7533. [CrossRef] [PubMed]

13. Li, J.; Lv, Q.; Zhang, M.; Wang, T.; Kawamoto, K.; Chen, S.; Zhang, B. Effects of atmospheric dynamics and aerosols on the fraction of supercooled water clouds. Atmos. Chem. Phys. 2017, 17, 1847-1863. [CrossRef]

14. Hua, S.; Liu, Y.; Jia, R.; Chang, S.; Wu, C.; Zhu, Q.; Shao, T.; Wang, B. Role of Clouds in Accelerating Cold-Season Warming During 2000-2015 over the Tibetan Plateau. Int. J. Climatol. 2018, 38, 4950-4966. [CrossRef]

15. Huang, J.; Minnis, P.; Lin, B.; Wang, T.; Yi, Y.; Hu, Y.; Sun-Mack, S.; Ayers, K. Possible influences of Asian dust aerosols on cloud properties and radiative forcing observed from MODIS and CERES. Geophys. Res. Lett. 2006, 33, L06824. [CrossRef]

16. Liu, Y.; Huang, J.; Shi, G.; Takamura, T.; Khatri, P.; Bi, J.; Shi, J.; Wang, T.; Wang, X.; Zhang, B. Aerosol optical properties and radiative effect determined from sky-radiometer over Loess Plateau of Northwest China. Atmos. Chem. Phys. 2011, 11, 11455-11463. [CrossRef]

17. Li, Z.; Guo, J.; Ding, A.; Liao, H.; Liu, J.; Sun, Y.; Wang, T.; Xue, H.; Zhang, H.; Zhu, B. Aerosol and boundary-layer interactions and impact on air quality. Natl. Sci. Rev. 2017, 4, 810-833. [CrossRef]

18. Li, J.; Huang, J.; Stamnes, K.; Wang, T.; Lv, Q.; Jin, H. A global survey of cloud overlap based on CALIPSO and CloudSat measurements. Atmos. Chem. Phys. 2015, 15, 519-536. [CrossRef]

19. Chen, S.; Jiang, N.; Huang, J.; Zang, Z.; Guan, X.; Ma, X.; Luo, Y.; Li, J.; Zhang, X.; Zhang, Y. Estimations of indirect and direct anthropogenic dust emission at the global scale. Atmos. Environ. 2018, 200, 50-60. [CrossRef]

20. Guo, J.; Liu, H.; Li, Z.; Rosenfeld, D.; Jiang, M.; Xu, W.; Jiang, J.; He, J.; Chen, D.; Min, M.; et al. Aerosol-induced changes in the vertical structure of precipitation: A perspective of TRMM precipitation radar. Atmos. Chem. Phys. 2018, 18, 13329-13343. [CrossRef]

21. Zhu, Q.; Liu, Y.; Jia, R.; Hua, S.; Shao, T.; Wang, B. A numerical simulation study on the impact of smoke aerosols from Russian forest fires on the air pollution over Asia. Atmos. Environ. 2018, 182, 263-274. [CrossRef]

22. Guo, J.; Deng, M.; Lee, S.S.; Wang, F.; Li, Z.; Zhai, P.; Liu, H.; Lv, W.; Yao, W.; Li, X. Delaying precipitation and lightning by air pollution over the Pearl River Delta. Part I: Observational analyses. J. Geophys. Res. Atmos. 2016, 121, 6472-6488. [CrossRef]

23. Liu, Y.; Zhu, Q.; Huang, J.; Hua, S.; Jia, R. Impact of dust-polluted convective clouds over the Tibetan Plateau on downstream precipitation. Atmos. Environ. 2019, 209, 67-77. [CrossRef] 
24. Stephens, G. Cloud feedbacks in the climate system: A critical review. J. Clim. 2005, 18, 237-273. [CrossRef]

25. Leyton, S.M.; Fritsch, J.M. The impact of high-frequency surface weather observations on short-term probabilistic forecasts of ceiling and visibility. J. Appl. Meteorol. 2004, 43, 145-156. [CrossRef]

26. Inoue, M.; Fraser, A.D.; Phillips, H.E. An assessment of numerical weather prediction-derived low-cloud-base height forecasts. Wea. Forecast. 2015, 30, 486-497. [CrossRef]

27. Costa-Surós, M.; Calbó, J.; González, J.A.; Martin-Vide, J. Behavior of cloud base height from ceilometer measurements. Atmos. Res. 2013, 127, 64-76. [CrossRef]

28. L'Ecuyer, T.S.; Jiang, J. Touring the atmosphere aboard the A-Train. Phys. Today 2010, 63, 36-41. [CrossRef]

29. Leeuw, G.; Kokhanovsky, A.; Cermak, J. Remote sensing of aerosols and clouds: Techniques and applications (editorial to special issue in Atmospheric Research). Atmos. Res. 2012, 113, 40-42. [CrossRef]

30. Hutchison, K.D. The retrieval of cloud base heights from MODIS and three-dimensional cloud fields from NASA's EOS Aqua mission. Int. J. Remote. Sens. 2002, 23, 5249-5265. [CrossRef]

31. Hutchison, K.D.; Wong, E.; Ou, S.C. Cloud base heights retrieved during night-time conditions with MODIS data. Int. J. Remote. Sens. 2006, 27, 2847-2862. [CrossRef]

32. Kuji, M.; Nakajima, T.Y.; Mukai, S. Retrieval of cloud geometrical properties using optical remote sensing data. Proc. SPIE 2000. [CrossRef]

33. Borg, L.A.; Holz, R.E.; Turner, D.D. Investigating cloud radar sensitivity to optically thin cirrus using collocated Raman lidar observations. Geophys. Res. Lett. 2011, 38, L05807. [CrossRef]

34. Sharma, S.; Vaishnav, R.; Shukla, M.V.; Kumar, P.; Thapliyal, P.K.; Lal, S.; Acharya, Y.B. Evaluation of cloud base height measurements from Ceilometer CL31 and MODIS satellite over Ahmedabad, India. Atmos. Meas. Technol. 2015, 8, 11729-11752. [CrossRef]

35. Liang, Y.; Sun, X.; Miller, S.D.; Li, H.; Zhou, Y.; Zhang, R.; Li, S. Cloud Base Height Estimation from ISCCP Cloud-Type Classification Applied to A-Train Data. Adv. Meteorol. 2017. [CrossRef]

36. Oh, S.B.; Kim, Y.H.; Cho, C.H.; Lim, E. Verification and correction of cloud base and top height retrievals from Ka-band cloud radar in Boseong, Korea. Adv. Atmos. Sci. 2016, 33, 73-84. [CrossRef]

37. Zhang, J.Q.; Xia, X.A.; Chen, H.B. A comparison of cloud layers from ground and satellite active remote sensing at the Southern Great Plains ARM site. Adv. Atmos. Sci. 2017, 34, 347-359. [CrossRef]

38. Martucci, G.; Milroy, C.; O’Dowd, C.D. Detection of cloud-base height using Jenoptik CHM15K and Vaisala CL31 ceilometers. J. Atmos. Ocean. Technol. 2010, 27, 305-318. [CrossRef]

39. Poore, K.D.; Wang, J.; Rossow, W.B. Cloud layer thicknesses from a combination of surface and upper-air observations. J. Clim. 1995, 8, 550-568. [CrossRef]

40. Yan, W.; Han, D.; Lu, W.; Lei, X. Research of cloud base height retrieval based on COSMIC occultation sounding data. Chin. J. Geophys. 2012, 55, 1-15. [CrossRef]

41. Zhang, J.; Chen, H.; Li, Z.; Fan, X.; Peng, L.; Yu, Y.; Cribb, M. Analysis of cloud layer structure in Shouxian, China using RS92 radiosonde aided by $95 \mathrm{GHz}$ cloud radar. J. Geophys. Res. 2010, 115, D00K30. [CrossRef]

42. Zhang, Y.; Zhang, L.; Guo, J.; Feng, J.; Cao, L.; Wang, Y.; Zhou, Q.; Li, L.; Li, B.; Xu, H.; et al. Climatology of cloud-base height from long-term radiosonde measurements in China. Adv. Atmos. Sci. 2018, 35, 158-168. [CrossRef]

43. Kassianov, E.I.; Long, C.N.; Christy, J. Cloud-Base-Height Estimation from Paired Ground-Based Hemispherical Observations. J. Appl. Meteorol. 2005, 44, 1221-1233. [CrossRef]

44. Maturilli, M.; Ebell, K. Twenty-five years of cloud base height measurements by ceilometer in Ny-Ålesund, Svalbard. Earth Syst. Sci. Data 2018, 10, 1451-1456. [CrossRef]

45. Wang, Z.; Wang, Z.H.; Cao, X. Consistency analysis for cloud vertical structure derived from millimeter cloud radar and radiosonde profiles. Acta. Meteorol. Sin. 2016, 74, 815-826.

46. Forsythe, J.; Haar, T.V.; Reinke, D. Cloud-base height estimates using a combination of meteorological satellite imagery and surface reports. J. Appl. Meteorol. 2000, 39, 2336-2347. [CrossRef]

47. Barker, H.W. Estimating cloud field albedo using one-dimensional series of optical depth. J. Atmos. Sci. 1996, 53, 2826-2837. [CrossRef]

48. Berg, L.; Stull, R. Accuracy of point and line measures of boundary layer cloud amount. J. Appl. Meteor. 2002, 41, 640-650. [CrossRef]

49. Kassianov, E.I.; Long, C.; Ovtchinnikov, M. Cloud sky cover versus cloud fraction: Whole-sky simulations and observations. J. Appl. Meteor. 2005, 44, 86-98. [CrossRef] 
50. Chernykh, I.V.; Eskridge, R.E. Determination of cloud amount and level from radiosonde soundings. J. Appl. Meteorol. 1996, 35, 1362-1369. [CrossRef]

51. Craven, J.P.; Jewell, R.E.; Brooks, H.E. Comparison between observed convective cloud-base heights and lifting condensation level for two different lifted parcels. Wea. Forecast. 2002, 17, 885-890. [CrossRef]

52. Stull, R.B.; Eloranta, E. A case study of the accuracy of routine, fair-weather cloud-base reports. Natl. Wea. Dig. 1985, 10, 19-24.

53. Zhang, Y.; Klein, S.A. Factors controlling the vertical extent of fair-weather shallow cumulus clouds over land: Investigation of diurnal-cycle observations collected at the ARM Southern Great Plains site. J. Atmos. Sci. 2013, 70, 1297-1315. [CrossRef]

54. Romps, D.M. Exact expression for the lifting condensation level. J. Atmos. Sci. 2017, 74, 3891-3900. [CrossRef]

55. Kleet, J.D. Stable analytical inversion solution for processing lidar returns. Appl. Opt. 1981, 20, $211-220$. [CrossRef] [PubMed]

56. Collis, R.T.H.; Russell, P.B. Lidar measurement of particles and gases by elastic backscateringand dif ferential absorption. In Laser Monitoring of the Atmosphere; Springer: Berlin/Heidelberg, Germany, 1976; pp. 71-151.

57. Chambers, L.H.; Lin, B.; Young, D.F. Examination of new CERES data for evidence of tropical iris feedback. J. Clim. 2002, 15, 3719-3726. [CrossRef]

58. Dee, D.P.; Uppala, S.M.; Simmons, A.J.; Berrisford, P.; Poli, P.; Kobayashi, S.; Andrae, U.; Balmaseda, M.A.; Balsamo, G.; Bauer, P.; et al. The ERA-Interim reanalysis: Configuration and performance of the data assimilation system. Quart. J. R. Meteor. Soc. 2011, 137, 553-597. [CrossRef]

59. Iribarne, J.V.; Cho, H.-R. Atmospheric Physics; Reidel: Dordrecht, The Netherlands, 1980; ISBN 90-277-1033-3.

60. Chernykh, I.; Aldukhov, O. Vertical distribution of cloud layers from atmospheric radiosounding data. Izv. Atmos. Ocean. Phys. 2004, 40, 41-53.

(C) 2019 by the authors. Licensee MDPI, Basel, Switzerland. This article is an open access article distributed under the terms and conditions of the Creative Commons Attribution (CC BY) license (http://creativecommons.org/licenses/by/4.0/). 